\title{
(3) Tailoring of Polarizing Agents in the bTurea Series for Cross-Effect Dynamic Nuclear Polarization in Aqueous Media
}

\author{
Claire Sauvée, ${ }^{[b]}$ Gilles Casano, ${ }^{[b]}$ Sébastien Abel, ${ }^{[b]}$ Antal Rockenbauer, ${ }^{[c]}$ \\ Dimitry Akhmetzyanov, ${ }_{1}^{[f]}$ Hakim Karoui, ${ }^{[b]}$ Didier Siri, ${ }_{1}^{[b]}$ Fabien Aussenac, ${ }_{1}^{[\mathrm{e}]}$ Werner Maas, ${ }_{1}^{[\mathrm{d}]}$ \\ Ralph T. Weber, ${ }^{[\mathrm{d}]}$ Thomas Prisner, ${ }^{[\mathrm{f}]}$ Mélanie Rosay, ${ }^{[\mathrm{d}]}$ Paul Tordo, ${ }^{*[\mathrm{a}]}$ and Olivier Ouari ${ }^{*[\mathrm{a}]}$
}

Abstract: A series of 18 nitroxide biradicals derived from bTurea has been prepared, and their enhancement factors $\varepsilon\left({ }^{1} \mathrm{H}\right)$ in cross-effect dynamic nuclear polarization (CE DNP) NMR experiments at 9.4 and $14.1 \mathrm{~T}$ and $100 \mathrm{~K}$ in a DNP-optimized glycerol/water matrix ("DNP juice") have been studied. We observe that $\varepsilon\left({ }^{1} \mathrm{H}\right)$ is strongly correlated with the substituents on the polarizing agents, and its trend is discussed in terms of different molecular parameters: solubility, average e-e distance, relative orientation of the nitroxide moiet- ies, and electron spin relaxation times. We show that too short an e-e distance or too long a $T_{1 \mathrm{e}}$ can dramatically limit $\varepsilon\left({ }^{1} \mathrm{H}\right)$. Our study also shows that the molecular structure of AMUPol is not optimal and its $\varepsilon\left({ }^{1} \mathrm{H}\right)$ could be further improved through stronger interaction with the glassy matrix and a better orientation of the TEMPO moieties. A new AMUPol derivative introduced here provides a better $\varepsilon\left({ }^{1} \mathrm{H}\right)$ than AMUPol itself (by a factor of ca. 1.2).

\section{Introduction}

During the last two decades, dynamic nuclear polarization (DNP) coupled with solid-state NMR has evolved into one of the most efficient methods to overcome the limitations resulting from the intrinsic poor sensitivity of NMR. The DNP method exploits the microwave-driven $(\mu \mathrm{w})$ transfer of polarization from the electron spin of a paramagnetic center (polarizing agent) to surrounding nuclei. DNP experiments that achieve even a fraction of the theoretical maximum sensitivity en-

[a] Prof. P. Tordo, Dr. O. Ouari

Aix-Marseille Université, CNRS, ICR UMR 7273

13397, Marseille cedex 20 (France)

E-mail:paul.tordo@univ-amu.fr olivier.ouari@univ-amu.fr

[b] C. Sauvée, Dr. G. Casano, Dr. S. Abel, Dr. H. Karoui, Prof. D. Siri Aix-Marseille Université, CNRS, ICR UMR 7273

13397, Marseille cedex 20 (France)

[c] Prof. A. Rockenbauer

Institute of Materials and Environmental Chemistry, Hungarian Academy of Sciences

Department of Physics, Budapest University of Technology and Economics and MTA-BME Condensed Matter Research Group, Budafoki ut 8, 1111 Budapest (Hungary)

[d] Dr. W. Maas, Dr. R. T. Weber, Dr. M. Rosay

Bruker BioSpin Corporation, 15 Fortune Drive, Billerica, Massachusetts 01821 (USA)

[e] Dr. F. Aussenac

Bruker BioSpin S.A.S. 34 rue de l'industrie, 67166 Wissembourg (France)

[f] Dr. D. Akhmetzyanov, Prof. T. Prisner

Institute of Physical and Theoretical Chemistry, Goethe University Frankfurt, Max-von-Laue Str. 7, 60438 Frankfurt-am-Main (Germany)

$\square$ Supporting information and $O R C I D(s)$ from the author(s) for this article are iD available on the WWW under http://dx.doi.org/10.1002/chem.201504693. hancement $\gamma_{\mathrm{e}} / \gamma_{\mathrm{n}}\left(658\right.$ for ${ }^{1} \mathrm{H}, 2617$ for $\left.{ }^{13} \mathrm{C}\right)$ can assist in overcoming the low sensitivity of NMR and achieving breakthroughs in the application of the technique to investigate previously inaccessible systems. Applications of DNP-enhanced solid-state NMR spectroscopy under magic-angle spinning conditions (DNP/MAS NMR) have led to great progress, ${ }^{[1]}$ prompting and taking advantage of rapid developments in theoretical models. ${ }^{[2]}$ DNP signal enhancement factors $\varepsilon$ (defined as the ratio of the integrated intensities between $\mu \mathrm{w}$ on and $\mu \mathrm{w}$ off spectra) of up to around 50 and 100 have been reported (at 9.4 T, $263 \mathrm{GHz}, 100 \mathrm{~K}$ ) for DNP applications on biological solids $^{[3]}$ and hybrid or inorganic materials, ${ }^{[4]}$ respectively. The key to all these applications is obtaining large DNP enhancements that translate into greatly improved sensitivity for magnetic resonance experiments. As a result, there is currently great interest in understanding instrumental and experimental factors that influence DNP enhancements (e.g., MAS frequency, microwave frequency and power, temperature). However, the transferred polarization is ultimately derived from the polarizing agent (PA), the structural and magnetic characteristics of which are of the upmost importance with regard to the value of $\varepsilon$. Indeed, besides instrumentation, the PA is a second and equally critical component of the DNP methodology.

Initial high-field DNP/MAS NMR experiments were performed on the basis of a cross-effect (CE) polarization transfer mechanism, employing solutions doped with high concentrations of mono-radical nitroxide species $(40-100 \mathrm{~mm})$ such as TEMPO. ${ }^{[5]}$ In 2004, a significant step towards the development of efficient CE DNP polarizing agents was achieved by Griffin et al. They showed, using a series of bis-TEMPO- $n$-ethylene glycol (BTnE) dinitroxides, that biradical polarizing agents yielded significant improvements in CE polarization efficiency. ${ }^{[6]}$ Subsequently, 


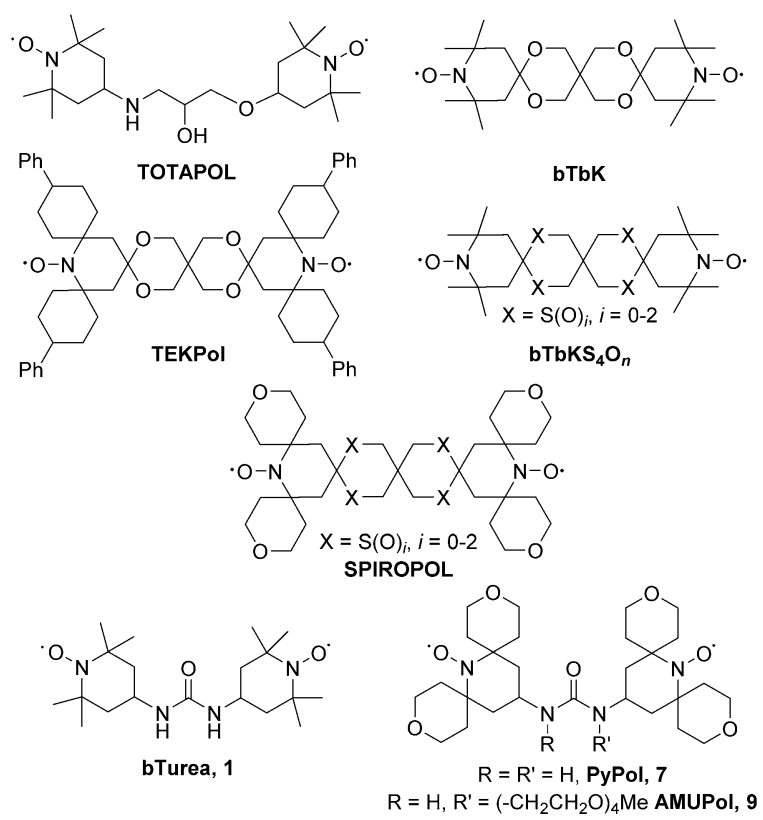

Scheme 1. Structures of TOTAPOL, bTbK, TEKPol, bTbKS ${ }_{4} \mathrm{O}_{n}$, SPIROPOL, bTurea, PyPol, and AMUPol.

they introduced the water-soluble biradical TOTAPOL $^{[7]}$ (Scheme 1), which has good solubility and stability in aqueous media containing glycerol and salts at concentrations typically found in protein solutions. Outstanding results were obtained using TOTAPOL as an exogenous polarizing agent in DNP/ ssNMR applications on various biological systems. However, TOTAPOL was shown to have a relatively flexible structure, ${ }^{[8]}$ which is detrimental to the frequency matching condition required for an efficient CE mechanism, and the DNP enhancements observed with TOTAPOL $\left(\varepsilon\left({ }^{1} \mathrm{H}\right)<80\right.$ on standard samples at $9.4 \mathrm{~T}, 263 \mathrm{GHz} E P R, 100 \mathrm{~K}$ ) remain far from the theoretical limit (658), and decrease rapidly at $T>100 \mathrm{~K} \cdot{ }^{[9]}$ A step forward was achieved when, in collaboration with Griffin's group, we introduced $\mathrm{bTbK}^{[10]}$ (Scheme 1), a biradical in which two TEMPO moieties are linked by a tether that rigidly holds a quasi-orthogonal relative orientation of the TEMPO $g$ tensors, which favors the CE frequency matching condition. ${ }^{[8,11]}$ All things being equal, bTbK is 1.4 times more efficient than TOTA$\mathrm{POL}$; however, its poor solubility in water restricts its use to DNP experiments performed in organic matrices. Improvements of the water solubility through chemical modifications $\left(\mathrm{bTbKS}_{4} \mathrm{O}_{n}{ }^{[12]}\right.$ SPIROPOL; ${ }^{[13]}$ Scheme 1) or through the formation of complexes with various hosts have been reported. ${ }^{[14]}$ In a glycerol/water matrix, compared to TOTAPOL, $10 \%$ and $20 \%$ increases in $\varepsilon$ were observed with bTbKS $_{4} \mathrm{O}_{n}$ and SPIROPOL, respectively. The best improvement, $\varepsilon_{\mathrm{bTbK}} / \varepsilon_{\mathrm{TOTAPOL}}=2.4$, was observed in a protonated glycerol/water matrix, containing bTbK $(9 \mathrm{~mm})$ that had been previously solubilized in water (up to $20 \mathrm{~mm}$ ) through complexation with a $\beta$-cyclodextrin modified with sulfobutyl groups. ${ }^{[14 a]}$

In the course of our search for new CE DNP polarizing agents, we have prepared and tested various dinitroxides. ${ }^{[15]}$ Among these dinitroxides, bTurea (Scheme 1), first described in
$1965,{ }^{[16]}$ has retained our attention. bTurea is poorly soluble in glycerol/water (60:40) $(<3 \mathrm{~mm})$; however, we found that at $10 \mathrm{~mm}$ in $\left[\mathrm{D}_{6}\right] \mathrm{DMSO} / \mathrm{D}_{2} \mathrm{O} / \mathrm{H}_{2} \mathrm{O}(60: 30: 10, \mathrm{v} / \mathrm{v} / \mathrm{v})$ it is $20 \%$ more efficient than TOTAPOL. By various chemical modifications, we have prepared a large series of water-soluble (up to $50 \mathrm{~mm}$ ) bTurea derivatives, and we recently briefly described ${ }^{[17]}$ PyPol 7 and AMUPol 9 (Scheme 1), which in bulk glycerol/water (60:40) frozen solutions proved to be significantly more efficient than TOTAPOL. The highest enhancement was obtained with AMUPol $\left(\varepsilon_{\mathrm{H}} \approx 240\right.$ at $9.4 \mathrm{~T}, 100 \mathrm{~K} ; \varepsilon_{\mathrm{H}} \approx 400^{[18]}$ at $\left.8.9 \mathrm{~T}, 80 \mathrm{~K}\right)$, making it currently the most efficient polarizing agent for DNP biological applications in water/glycerol. The higher DNP performance of AMUPol compared to that of TOTAPOL highlights the extreme sensitivity of the CE efficiency to molecular structure. However, at $9.4 \mathrm{~T}$ and around $100 \mathrm{~K}$, the efficiency of AMUPol still represents only $38 \%$ of the theoretical maximum polarization transfer; moreover, it deceases rapidly at either higher temperatures $(14 \%$ at $160 \mathrm{~K}$ ) or higher fields (ca. $19 \%$ at $14.1 \mathrm{~T}, 100 \mathrm{~K}$; ca. $6 \%$ at $18.8 \mathrm{~T}, 100 \mathrm{~K}$ ). The observed decrease with increasing magnetic field is much larger than expected if, as predicted, the CE DNP efficiency scales with the reciprocal of the proton Larmor frequency $\left(\omega_{\mathrm{OH}}{ }^{-1}\right)$.

At a given magnetic field, besides the structure of the polarizing agent, sample preparation and many other experimental parameters (temperature, $\mu \mathrm{w}$ power, MAS frequency, and so on) significantly influence the resulting DNP enhancements. Recently, Emsley et al. ${ }^{[19]}$ showed that significant improvements could be achieved by incorporating dielectric solid particles into the samples. At $9.4 \mathrm{~T}$ and $105 \mathrm{~K}$, enhancements of up to $\varepsilon_{\mathrm{H}}=363$ were obtained for bulk AMUPol/glycerol/water solutions mixed with ground sapphire. However, the addition of the solid particles did not improve the absolute sensitivity, since the gain in $\varepsilon_{\mathrm{H}}$ was offset by a reduction in active sample volume. De Päepe et al. ${ }^{[20]}$ demonstrated unprecedented DNP and sensitivity enhancements with TOTAPOL and AMUPol in experiments performed at sample temperatures much lower than $100 \mathrm{~K}$.

Although much effort has already been devoted to the design of efficient nitroxide-based CE DNP polarizing agents, ${ }^{[6,7,10,12-15,17,18,21]}$ there is still significant room for improvement. The extreme sensitivity of CE efficiency on the polarizing agent has been discussed in terms of different parameters: dipolar coupling (i.e., interelectron distance), $g$ tensor orientations, solubility in water, relaxation behavior, and conformational flexibility. However, to the best of our knowledge, the influence of these parameters on a large series of polarizing agents belonging to the same class of compounds has never been investigated in a water/glycerol matrix. Herein, we report the preparation of a large series of bTurea derivatives (Schemes 2-6) and discuss the influence of molecular parameters on their CE DNP performances. We highlight the achievement of PyPolPEG2OH (Scheme 4), which at 9.4 T and $100 \mathrm{~K}$ exhibits the best enhancement $\left(\varepsilon_{\mathrm{H}}=303\right)$ hitherto obtained in socalled "DNP juice". 


\section{Results and Discussion}

\section{Water-soluble bTurea derivatives bearing PEG chains}

Synthesis: To improve the water solubility of bTurea, we first prepared bTurea derivatives bearing one (compounds $\mathbf{2}, \mathbf{3}$, and 4. Scheme 2) or two PEG chains (compounds 5 and 6, Scheme 3) on the urea nitrogen atoms. For $n=2,4,8-12$, con-

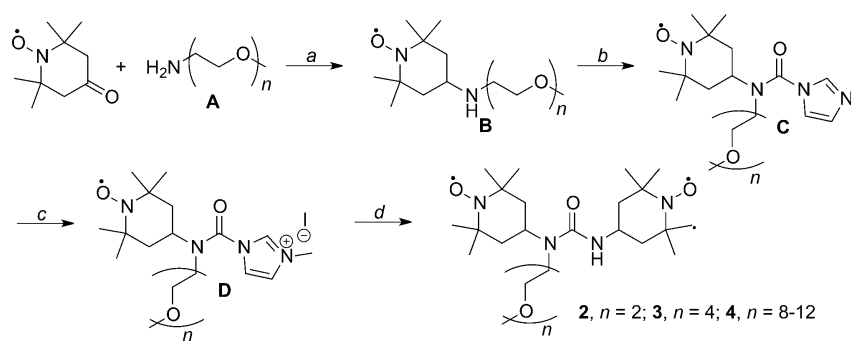

Scheme 2. Synthetic route to 2, 3, and 4; a) reductive amination, b) CDI, c) Mel, d) 4-amino-TEMPO (for details and compound characterization, see Section 4.1 in the Supporting Information).

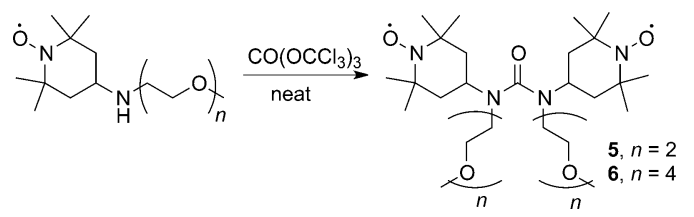

Scheme 3. Synthetic route to 5 and $\mathbf{6}$ (for details and compound characterization, see in the Supporting Information).

densation of 4-amino-TEMPO with the corresponding carbamoylimidazolium (D, Scheme 2) yielded bTureaPEG2 2, bTureaPEG4 3, and bTureaPEG10 4 in reasonable yields. However, this procedure failed when we tried to append two PEG chains on bTurea. Compounds $\mathbf{5}$ and $\mathbf{6}$ were obtained in very poor yields using the conditions shown in Scheme 3. Compared to the solubility of bTurea $(<3 \mathrm{~mm})$ in glycerol/water $(60: 40)$, those of the prepared PEGylated bTureas were significantly increased. However, at least four ethylene glycol units $(n=4)$ were needed to reach the $10 \mathrm{~mm}$ solubility in water routinely used for DNP experiments.

EPR studies: X-band EPR spectra of $1 \mathrm{~mm}$ aqueous solutions of bTurea and compounds 2-6 were recorded at $293 \mathrm{~K}$. The mono-PEGylated bTureas 2, 3, and $\mathbf{4}$ show EPR spectra similar to that of bTurea, characteristic of dinitroxides exhibiting exchange $J$ and hyperfine $A_{N}$ couplings of the same order of magnitude, for which spectra composed of up to 15 lines would be expected ${ }^{[22]}$ (Figure 1 and Tables S2 and S3, Figure S5 in the Supporting Information). No significant changes in the EPR spectra were observed when the temperature was increased from $283 \mathrm{~K}$ to $350 \mathrm{~K}$ (data not shown). From the calculated spectra, the following average parameters were obtained (Table S3 in the Supporting Information): $A_{\mathrm{N}} \approx 17 \mathrm{G}, J \approx 24 \mathrm{G}$, with a narrow $J$ scattering, $\delta J<2.2 \mathrm{G}$. The lack of influence of temperature on the EPR spectra and the low variations in $J$ values suggest a rigid structure of the urea moiety, in agree-

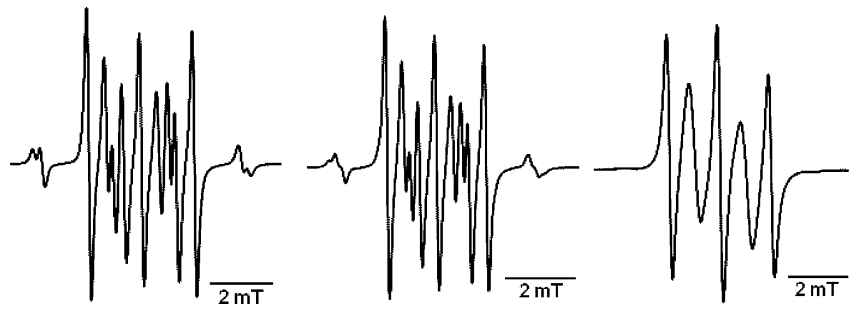

Figure 1. X-band EPR spectra ( $1 \mathrm{~mm}$ aqueous solutions at $293 \mathrm{~K}$ ) of bTurea (left), bTureaPEG10 4 (center), and bTureadiPEG2 5 (right).

ment with the results of studies on conformational analysis and rotational barriers for alkyl-substituted ureas. ${ }^{[23]}$

The EPR spectral features of bTureadiPEG2 and bTureadiPEG4 are very different from those of bTurea and mono-PEGylated bTureas (Figure 1), and are characteristic of a $J \gg A_{N}(J>$ $5 A_{N}$ ) regime and a strong $J$ modulation. ${ }^{[22]}$ The observed EPR data suggest that the preferred conformers of bTurea and mono-PEGylated bTureas exhibit very similar and rigid bTurea backbone geometries. However, for bTureadiPEG2 and bTureadiPEG4, the steric strain resulting from the introduction of a second PEG chain induces significant geometry changes, favoring conformers with shorter electron-electron distances and higher $J$ values.

CE DNP studies: bTurea and compounds 2-6 were tested as DNP polarizing agents in DNP/MAS NMR experiments at $9.4 \mathrm{~T}$ (EPR $263 \mathrm{GHz}$, NMR $400 \mathrm{MHz}$ ). The results are presented in Table 1.

The DNP enhancements achieved with compounds 2, 3, and 4 were twice as high as that achieved with bTurea. According to the EPR spectra, bTurea and compounds 2, 3, and 4, show very similar spin exchange, which is almost independent of temperature. It is thus reasonable to assume that, for these compounds, both the average e-e distances $\left\langle R_{\mathrm{ee}}\right\rangle$ and hence the dipolar couplings have similar values. We performed molecular dynamics (MD) calculations on bTurea 1 and bTureaPEG2 2 to estimate $\left\langle R_{\mathrm{ee}}\right\rangle$ and the average angle $\langle\theta\rangle$ between lines normal to the average nodal planes of the TEMPO moieties. These lines are parallel to the direction of the nitrogen $2 p_{z}$

Table 1. DNP/MAS NMR experiments at $263 \mathrm{GHz}, 8 \mathrm{kHz}$ MAS, $101 \mathrm{~K}$, in $\left[D_{8}\right]$ glycerol/ $\mathrm{D}_{2} \mathrm{O} / \mathrm{H}_{2} \mathrm{O}(60: 30: 10)$ with compounds 2-6 (Schemes 2 and 3).

\begin{tabular}{|llllr|} 
Compounds & $\mathrm{MW}^{\text {[a] }}$ & $\begin{array}{l}{[\mathrm{C}]^{[\mathrm{b}]}} \\
{[\mathrm{mM}]}\end{array}$ & $\begin{array}{l}\varepsilon\left({ }^{1} \mathrm{H}\right)^{[\mathrm{cc}]} \\
{[-]}\end{array}$ & $\begin{array}{c}T_{\mathrm{DNP}}{ }^{[\mathrm{d}]} \\
{[\mathrm{s}]}\end{array}$ \\
\hline bTurea, 1 & 368.5 & $<3$ & 62 & 16.5 \\
bTureaPEG2, 2 & 470.65 & 6.2 & 123 & 6.4 \\
bTureaPEG4, 3 & 558.75 & 12.4 & 120 & 1.6 \\
bTureaPEG10, 4 & 850.4 & 10 & 120 & 2.6 \\
bTureadiPEG2, 5 & 572.8 & 10 & 44 & 2.8 \\
bTureadiPEG4, 6 & 749.0 & 10 & 37 & 5.2 \\
\hline
\end{tabular}

[a] Molecular weight. [b] Concentration. [c] The DNP enhancement $\varepsilon\left({ }^{1} \mathrm{H}\right)$ corresponds to the ratio of the NMR signal intensities with and without microwave irradiation. [d] Polarization build-up time; $\varepsilon\left({ }^{1} \mathrm{H}\right)$ and $T_{\mathrm{DNP}}$ were determined from $\mathrm{CP}$ on solvent ${ }^{13} \mathrm{C}$ natural abundance. 
orbital and their relative orientation is correlated with that of the two $g$ tensors. MD simulations in water at $278 \mathrm{~K}$, over periods of $200 \mathrm{~ns}$, were performed using the Gromacs 5.0.4 package $^{[24]}$ (see details and comments in Section 1 of the Supporting Information). The results, $\left\langle R_{\mathrm{ee}}\right\rangle=11.6 \pm 0.1 \AA$ and $11.5 \pm$ $0.1 \AA ;\langle\theta\rangle=27.9 \pm 16.1^{\circ}$ and $31.9 \pm 15^{\circ}$ for 1 and 2 , respectively, are consistent with the rigidity of the bTurea backbone and indicate a fluctuation of the relative orientation of the $g$ tensors. The EPR and MD results showed that the e-e dipole coupling, the spin exchange, and the relative orientation of the $g$ tensors have almost consistent values within the series 1-4. Furthermore, since no significant difference would be expected in the electon spin relaxation times of bTurea and bTureaPEG2 2, the superior DNP performance of $\mathbf{2}$ as compared to bTurea can be mainly attributed to its better solubility in the glycerol/water mixture, which allows its use at higher concentration. For bTureaPEG2 2 and bTureaPEG4 3, we observed that decreasing the concentration does not significantly affect the DNP enhancement; however, the DNP build-up time increases, leading to a significant decrease in the overall sensitivity of the NMR acquisition.

For bTureadiPEG2 5 and bTureadiPEG4 6, the EPR spectra suggest important changes in the geometry of the bTurea backbone, resulting in shorter $\left\langle R_{\mathrm{ee}}\right\rangle$ and higher $J$ values. MD calculation on $\mathbf{5}$ led to two different conformational domains, $A$ and $B$ (Table $S 1$ in the Supporting Information), with the following characteristics: for $\mathrm{A},\left\langle R_{\mathrm{ee}}\right\rangle=11.45 \pm 0.15 \AA,\langle\theta\rangle=77 \pm$ $18^{\circ}$; for $\mathrm{B},\left\langle R_{\mathrm{ee}}\right\rangle=8.55 \pm 0.2 \AA,\langle\theta\rangle=37.6 \pm 12^{\circ}$. We extracted one conformer (bTureadiPEG2A and bTureadiPEG2B) from each domain, the geometries of which were optimized by DFT calculations. The energy of bTureadiPEG2B was calculated to be lower than that of bTureadiPEG2A $\left(\Delta E=1.3 \mathrm{kcalmol}^{-1}\right)$ and these DFT-optimized conformers exhibited the following characteristics: $R_{\mathrm{ee}}=11.37 \AA, \theta=77.1^{\circ}$ for bTureadiPEG2A; $R_{\mathrm{ee}}=$ $8.54 \AA, \theta=51.6^{\circ}$ for bTureadiPEG2B (Figure S3 in the Supporting Information). In a recent paper, Griffin et al. ${ }^{[25]}$ established that for the three-spin-1/2 $\left(S_{1} S_{2} l\right) C E$ process, the mixing of the spin states that is required for polarization transfer is optimal when Equation (1) is met.

$\omega_{\wedge} \approx \omega_{01}\left(1-D_{0}{ }^{2} / \omega_{0 \mid}^{2}\right)^{1 / 2}$

with $\omega_{\wedge}=\left|\omega_{0 s 1}-\omega_{0 s 2}\right|$ and $D_{0}=-(d+J)$, where $\omega_{0 s 1}, \omega_{0 s 2}$ and $\omega_{01}$ are the Larmor frequencies of the two electrons and the nucleus; $d$ and $J$ are the $\mathrm{e}^{-}-\mathrm{e}^{-}$dipolar and exchange couplings, respectively. If $d$ and $J$ are small compared to $\omega_{0,}$, Equation (1) can be further simplified to $\omega_{\wedge} \approx \omega_{01}-D_{0}{ }^{2} / 2 \omega_{01} \approx \omega_{01}$. This applies for compounds 2, 3, and 4, which have almost identical $\mathrm{e}^{-}-\mathrm{e}^{-}$dipolar couplings and $J$ couplings. The $J$ value estimated from their very similar EPR data is about $67 \mathrm{MHz}$, and the $d$ value estimated from the point dipole approximation using the MD-calculated distance $\left\langle R_{\mathrm{ee}}\right\rangle$ is about $35 \mathrm{MHz}$. However, for bTureadiPEG2, according to the simulation of its solution EPR spectrum, $J$ is about $250 \mathrm{MHz}$, and for the major conformers such as bTureadiPEG2B, $R_{\text {ee }}$ is estimated as $8.5 \AA$, which corresponds to a dipolar coupling $d$ of about $128 \mathrm{MHz}$. The much higher values of $J$ and $d$ for $\mathbf{5}$ compared with those of compounds 2, 3, and 4 probably account for the significant decrease in its DNP enhancement (Table 1).

Water-soluble bTurea derivatives with long electron spin relaxation times

Besides the geometry, the electronic relaxation properties of radical species used as polarizing agents are another key factor affecting the DNP process. ${ }^{[2, e, 4 e,]}$ The CE is a three-spin (two electrons, one nucleus) process that requires the saturation of one of the electron resonances to trigger electron spin polarization transfer to nuclei. The efficiency of the electron resonance saturation depends on the saturation factor $\left(s \propto T_{1 \mathrm{e}} \times T_{\mathrm{m}}\right)$; the higher the value of $s$, the more efficient the saturation will be. The electron relaxation of nitroxides in the $100 \mathrm{~K}$ regime in glassy solvents is driven by several mechanisms. Studies by $\mathrm{S}$. Eaton and co-workers ${ }^{[26 a]}$ established that the Raman process, which depends on molecular motion and libration, is the dominant mechanism of longitudinal relaxation $T_{1 \mathrm{e}}$. Libration of a molecule in a glassy matrix will depend on the molecular volume, which is likely to be approximately proportional to molecular weight. Libration decreases dramatically with increasing size of the molecule, and $T_{1 \mathrm{e}}$ of nitroxides has been shown to increase significantly with molecular weight. Libration also reflects the dependence of motion on intermolecular interaction, and $T_{1 \mathrm{e}}$ is higher in media such as a glycerol/water mixture, capable of fixing nitroxides through an extended hydrogen-bonding network. ${ }^{[26]}$ Molecular motion and libration also contribute to $T_{\mathrm{m}}$ and, for instance, above $80 \mathrm{~K}$ the rotation of methyl groups attached to the nitroxide or to solvent molecules can induce effective transverse relaxation. ${ }^{[25, d]}$ We have reported on the impact of electron relaxation times on DNP enhancement $(\varepsilon)$ in the bTbK series. ${ }^{[4 e, 1]}$ We showed, for instance, that compared to bTbK (MW $=441 \mathrm{~g} \mathrm{~mol}^{-1}$; Scheme 1), the saturation factor and the DNP enhancement for TEKPol $\left(\mathrm{MW}=905 \mathrm{~g} \mathrm{~mol}^{-1}\right.$; Scheme 1) are about 10 and 4 times higher, respectively (at 9.4 T, $100 \mathrm{~K}$, in glassy tetrachloroethane (TCE)). Capitalizing on this study, we sought water-soluble, high molecular weight bTurea derivatives with no methyl groups on the $C_{\alpha}$ carbons of the TEMPO moieties. We first replaced these $C_{\alpha}$ methyl groups with spirocyclohexyl moieties; however, the subsequent introduction of PEG chains was not sufficient to reach the $10 \mathrm{~mm}$ solubility required for most DNP applications. The solubility problem was overcome by replacing the $C_{\alpha}$ methyl groups with spirotetrahydropyranyl moieties, resulting in compounds 7-14 (Scheme 4).

Synthesis: Compounds 7, 13, and 14 were prepared by reacting bis(trichloromethyl)carbonate (triphosgene) with amines $\boldsymbol{a}, \boldsymbol{b}$, and $\boldsymbol{c}$, respectively (Scheme 4). Mono-PEGylated PyPols $\mathbf{8}$, 9, 10, and 12 and di-PEGylated PyPol 11 were prepared following the same strategies as used to prepare mono-PEGylated and di-PEGylated bTureas (Schemes 2 and 3).

EPR studies: The X-band EPR spectra of $1 \mathrm{~mm}$ aqueous solutions of compounds 7-14 were recorded at $293 \mathrm{~K}$ (see the Supporting Information). As for the bTureaPEGn derivatives, the EPR spectra of PyPol 7, mono-PEGylated PyPols (PyPolPEGn, $8(n=2), 9(n=4), 10(n=8-12)$, and PyPolPEG2OH 12) are almost identical (Figure 2) and characteristic of a $J \approx A_{N}$ regime. Average parameters of $A_{\mathrm{N}} \approx 16.5 \mathrm{G}, J \approx 16 \mathrm{G}$, with a scat- 


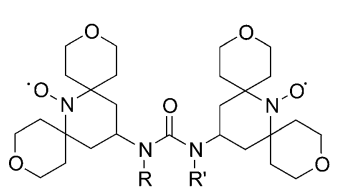

$\mathrm{R}=\mathrm{R}^{\prime}=\mathrm{H}$, PyPol, 7

$\mathrm{R}=\mathrm{H}_{1} \mathrm{R}^{\prime}=\left(-\mathrm{CH}_{2} \mathrm{CH}_{2} \mathrm{O}\right)_{2} \mathrm{Me}$, PyPoIPEG2, 8

$\mathrm{R}=\mathrm{H}, \mathrm{R}^{\prime}=\left(-\mathrm{CH}_{2} \mathrm{CH}_{2} \mathrm{O}\right)_{4} \mathrm{Me}$, PyPoIPEG4 (AMUPol), 9

$\mathrm{R}=\mathrm{H}, \mathrm{R}^{\prime}=\left(-\mathrm{CH}_{2} \mathrm{CH}_{2} \mathrm{O}\right)_{8-12} \mathrm{Me}$, PyPolPEG10, 10

$\mathrm{R}=\mathrm{R}^{\prime}=\left(-\mathrm{CH}_{2} \mathrm{CH}_{2} \mathrm{O}\right)_{4} \mathrm{Me}$, PyPoldiPEG4, 11

$\mathrm{R}=\mathrm{H}, \mathrm{R}^{\prime}=\left(-\mathrm{CH}_{2} \mathrm{CH}_{2} \mathrm{O}\right)_{2} \mathrm{CH}_{2} \mathrm{OH}$ PyPoIPEG2OH, 12

$\mathrm{R}=\mathrm{R}^{\prime}=-\mathrm{CH}_{3}$, PyPoldiMe, 13,

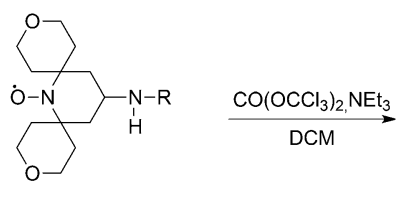

$\mathbf{a}, \mathrm{R}=\mathrm{H} ; \mathbf{b}, \mathrm{R}=\mathrm{Me} ; \mathbf{c}, \mathrm{R}=\mathrm{CD}_{3}$ $\mathrm{R}^{\prime}=-\mathrm{CD}_{3}$, PyPoldiCD, 14

Scheme 4. Compounds 7-14 (for synthetic details and compound characterization, see Section 4.2 in the Supporting Information).

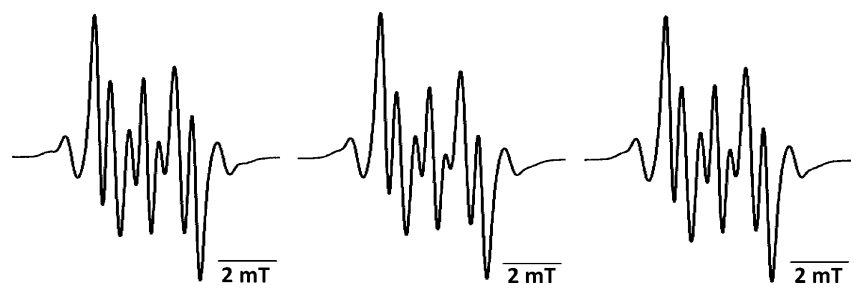

Figure 2. X-band EPR spectra ( $1 \mathrm{~mm}$ aqueous solutions at $293 \mathrm{~K}$ ) of PyPol 7 (left), PyPolPEG10 10 (center), and PyPolPEG2OH 12 (right).

tering $\delta J<4 \mathrm{G}$, were obtained from the calculated spectra (Table S3, Figure S5 in the Supporting Information). Compared with bTurea 1 and bTureaPEGn 2, 3, and 4, the increased linewidth can be attributed to unresolved long-range hyperfine couplings with $\gamma$ - and $\delta$-protons on the tetrahydropyranyl rings. As observed for bTureadiPEG4 6, the steric constraint resulting from the introduction of two PEG chains in PyPoldiPEG4 11 changes the geometry of the preferred conformers and the shape of the EPR spectrum. In the case of PyPoldiMe and PyPoldiCD ${ }_{3}$, the changes in molecular geometry due to the introduction of two $\mathrm{CH}_{3}\left(\mathrm{CD}_{3}\right)$ groups do not significantly affect the ratio $J / A_{N}$, and the shape of their EPR spectra is very similar to that of the spectrum of PyPol.

CE DNP studies and relaxation times: Compounds 7-14 were tested as DNP polarizing agents in DNP/ MAS NMR experiments at $9.4 \mathrm{~T}$ (EPR $263 \mathrm{GHz}$, NMR $400 \mathrm{MHz}$ ). Further measurements were also performed at $14.1 \mathrm{~T}$ (EPR $395 \mathrm{GHz}, \mathrm{NMR} 600 \mathrm{MHz}$ ) and $18.8 \mathrm{~T}$ (EPR $527 \mathrm{GHz}, \mathrm{NMR} 800 \mathrm{MHz}$ ). The results are presented in Table 2, which also includes values of $T_{1 \mathrm{e}}$ and $T_{\mathrm{m}}$ measured at $100 \mathrm{~K}$ and different frequencies. Most of the measurements were carried out at $95 \mathrm{GHz}$, but for AMUPol 9 we showed that relaxation times measured at 95 and $260 \mathrm{GHz}$ were comparable.

Introducing spirotetrahydropyranyl rings in place of methyl groups in the TEMPO moieties of bTurea 1 leads to PyPol 7, and results in a very large increase in $T_{\mathrm{m}}\left(T_{\mathrm{m}, 7} / T_{\mathrm{m}, 1} \approx 6.5\right)$ and a moderate increase in $T_{1 \mathrm{e}}$ $\left(T_{1 \mathrm{e}, 7} / T_{1 \mathrm{e}, 1} \approx 1.5\right)$. Moreover, $\mathrm{MD}$ calculations showed that for $\mathbf{1}$ and $\mathbf{7}$, both $\left\langle R_{\mathrm{ee}}\right\rangle$ and $\langle\theta\rangle$ are very similar $\left(\left\langle R_{\text {ee }}\right\rangle=11.6 \pm 0.1 \AA,\langle\theta\rangle=27.9 \pm 16.1^{\circ}\right.$ for $1 ;\left\langle R_{\text {ee }}\right\rangle=11.6 \pm 0.1 \AA$, $\langle\theta\rangle=26.9 \pm 15^{\circ}$ for 7$)$. Therefore, the far superior DNP enhancement obtained with PyPol 7 as compared to bTurea 1 results primarily from its much higher saturation factor (about tenfold higher), originating primarily from the longer $T_{\mathrm{m}}$.

In the series AMUPol 9, PyPolPEG10 10, and PyPolPEG2OH 12 , the $M D$ average values of $\left\langle R_{\mathrm{ee}}\right\rangle$ and $\langle\theta\rangle$ are identical (Table S1 in the Supporting Information) and the increase in DNP enhancement can be attributed to the increase in electron spin relaxation times. PyPoIPEG2OH has a slightly lower molecular weight than AMUPol, and its much higher $T_{1 \mathrm{e}}$ probably results from its better anchoring in the glycerol/water matrix through additional strong hydrogen bonds.

PyPoldiMe 13 is less soluble than PyPol in glycerol/water, and both $\varepsilon$ and relaxation times were measured at $5 \mathrm{~mm}$, the highest achievable concentration. MD calculations showed that the introduction of two methyl groups on the ureido linker does not significantly change the geometry of the bTurea backbone $\left(\left\langle R_{\text {ee }}\right\rangle=11.6 \pm 0.1 \AA\right.$ for PyPol $7 ; 11.4 \pm 0.1 \AA$ for PyPoldiMe 13). However, the steric interaction between the two methyl groups significantly changes the relative orientation of the TEMPO moieties $\left(\langle\theta\rangle=26.9 \pm 15^{\circ}\right.$ for $7 ; 71.7 \pm 13.7^{\circ}$ for 13). The superior DNP performance observed with 13 can be rationalized in terms of this more favorable orientation of the TEMPO moieties as well as a better saturation factor resulting from the lower concentration.

In the series PyPolPEG2 8, PyPolPEG4 9, and PyPolPEG10 10, the DNP performance increases with increasing molecular weight. As already mentioned, at $100 \mathrm{~K}$, increasing the molecular weight of nitroxides increases their electron relaxation times and therefore the enhancement factors, due to a better saturation of the DNP transitions. However, the increase of
Table 2. DNP/MAS NMR experiments at $263 \mathrm{GHz}, 395$ and $527 \mathrm{GHz}, 8 \mathrm{kHz} \mathrm{MAS}, 101 \mathrm{~K}$, in $\left[D_{8}\right]$ glycerol/ $\mathrm{D}_{2} \mathrm{O} / \mathrm{H}_{2} \mathrm{O}(60: 30: 10)$ with compounds 7-14 (10 m ; Scheme 4).

\begin{tabular}{|c|c|c|c|c|c|c|c|}
\hline Compounds & $\begin{array}{l}263 \mathrm{GHz} \\
\varepsilon\left({ }^{1} \mathrm{H}\right)^{[\mathrm{a}]} \\
{[-]}\end{array}$ & $\begin{array}{l}T_{\mathrm{DNP}}{ }^{[\mathrm{b}]} \\
{[\mathrm{s}]}\end{array}$ & $\begin{array}{l}395(52 \\
\varepsilon\left({ }^{1} \mathrm{H}\right)^{[\mathrm{a}]} \\
{[-]}\end{array}$ & $\begin{array}{l}\mathrm{GHz} \\
T_{\mathrm{DNP}} \\
{[\mathrm{s}]}\end{array}$ & $\begin{array}{l}T_{1 \mathrm{e}}^{[c]} \\
{[\mu s]}\end{array}$ & $\begin{array}{l}T_{\mathrm{m}}^{[\mathrm{c}]} \\
{[\mu \mathrm{s}]}\end{array}$ & $\begin{array}{l}\mathrm{MW} \\
{\left[\mathrm{g} \mathrm{mol}^{-1}\right]}\end{array}$ \\
\hline 1 bTurea $^{[\mathrm{d}]}$ & 62 & 16.5 & - & - & $306^{[\mathrm{e}]}$ & $1.8^{[\mathrm{e}]}$ & 368.5 \\
\hline 7 PyPol & 207 & 5.7 & $\begin{array}{l}128 \\
(35)\end{array}$ & $\begin{array}{c}8.7 \\
(12.3)\end{array}$ & $\begin{array}{l}470^{[\mathrm{e}]} \\
630^{[f]}\end{array}$ & $\begin{array}{c}12^{[\mathrm{e}]} \\
4^{[\mathrm{f}]}\end{array}$ & 536.7 \\
\hline 8 PyPolPEG2 & 217 & 4.9 & 123 & 6.4 & - & - & 638.8 \\
\hline 9 PyPolPEG4 (AMUPol) & 244 & 3.3 & $\begin{array}{r}128 \\
(37) \\
-\end{array}$ & $\begin{array}{l}4.9 \\
(7.0) \\
-\end{array}$ & $\begin{array}{l}460^{[\mathrm{e}]} \\
445^{[\mathrm{g}]} \\
500^{[\mathrm{f}]}\end{array}$ & $\begin{array}{l}10^{[\mathrm{e}]} \\
2.7^{[\mathrm{g}]} \\
2.7^{[\mathrm{f}]}\end{array}$ & 726.9 \\
\hline 10 PyPoIPEG10 & 257 & 2.8) & 145 & 4.1 & $586^{[\mathrm{g}]}$ & $2.8^{[g]}$ & 1039.6 \\
\hline 15 TetraPEG & 147 & 2.8 & 79 & 4.0 & $1195^{[\mathrm{g}]}$ & $2.4^{[g]}$ & 1461.8 \\
\hline 11 PyPoldiPEG4 & 133 & 2.5 & 79 & 3.4 & $445^{[\mathrm{g}]}$ & $2.7^{[\mathrm{g}]}$ & 917.1 \\
\hline 12 PyPoIPEG2OH & $\begin{array}{l}303 \\
305\end{array}$ & $\begin{array}{c}3.5 \\
10.0^{[]]}\end{array}$ & 123 & 4.9 & $691^{[\mathrm{g}]}$ & $3.0^{[g]}$ & 624.8 \\
\hline 13 PyPoldiMe ${ }^{[]}$ & 260 & 7.6 & 142 & 4.8 & $490^{[\mathrm{h}]}$ & $4.6^{[\mathrm{h}]}$ & 564.7 \\
\hline 14 PyPoldiCD ${ }^{[]]}$ & 250 & 4.6 & 139 & 6.5 & - & - & 570.8 \\
\hline
\end{tabular}

[a] $\varepsilon\left({ }^{1} \mathrm{H}\right)$ and polarization build-up time $T_{\mathrm{DNP}}$ determined from $\mathrm{CP}$ on solvent ${ }^{13} \mathrm{C}$ natural abundance. [b] Polarization build-up time $T_{\mathrm{DNp}}$ [c] In $\left[\mathrm{D}_{8}\right]$ glycerol/ $\mathrm{D}_{2} \mathrm{O} / \mathrm{H}_{2} \mathrm{O}$ (60:30:10). [d] [C] $\approx 3 \mathrm{~mm}$. [e] At $9.5 \mathrm{GHz}, 100 \mathrm{~K},[\mathrm{C}]=0.1 \mathrm{~mm}$. [f] At $260 \mathrm{GHz}, 100 \mathrm{~K}$, $[C]=10 \mathrm{~mm}$; for comparison, under the same experimental conditions, $T_{1 \mathrm{e}}=340 \mu \mathrm{s}$ and $T_{\mathrm{m}}=0.9 \mu \mathrm{s}$ for TEMPOL. [g] At $95 \mathrm{GHz}, 100 \mathrm{~K},[\mathrm{C}]=10 \mathrm{~mm}$. [h] At $95 \mathrm{GHz}, 100 \mathrm{~K}$, $[C]=5 \mathrm{~mm}$. [i] $[C]=5 \mathrm{~mm}$. 
$\varepsilon$ with increasing relaxation times is expected to reach a plateau ${ }^{[4]}$ and to determine the optimal relaxation times we prepared and tested a bTurea derivative bearing four PEG4 chains designated as TetraPEG 15 (Scheme 5). The shape of the $X$ band EPR spectrum of 15 (1 $\mathrm{mM}$ aqueous solution) recorded at $293 \mathrm{~K}$ is characteristic of dinitroxides exhibiting a spin-exchange interaction $J$ of the same order of magnitude as the hyperfine interaction $A_{\mathrm{N}}$ (Tables S2 and S3 in the Supporting Information). The $J$ value $(12.9 \mathrm{G})$ and its scattering $\delta J(2.0 \mathrm{G})$ are similar to those of AMUPol 9 (15.8 and $4.0 \mathrm{G}$ ) and PyPolPEG10 10 (15.8 and $3.2 \mathrm{G}$ ), and we can reasonably assume that for $\mathbf{9}$, 10 , and $15,\left\langle R_{\mathrm{ee}}\right\rangle$ and hence the dipolar coupling do not vary significantly.

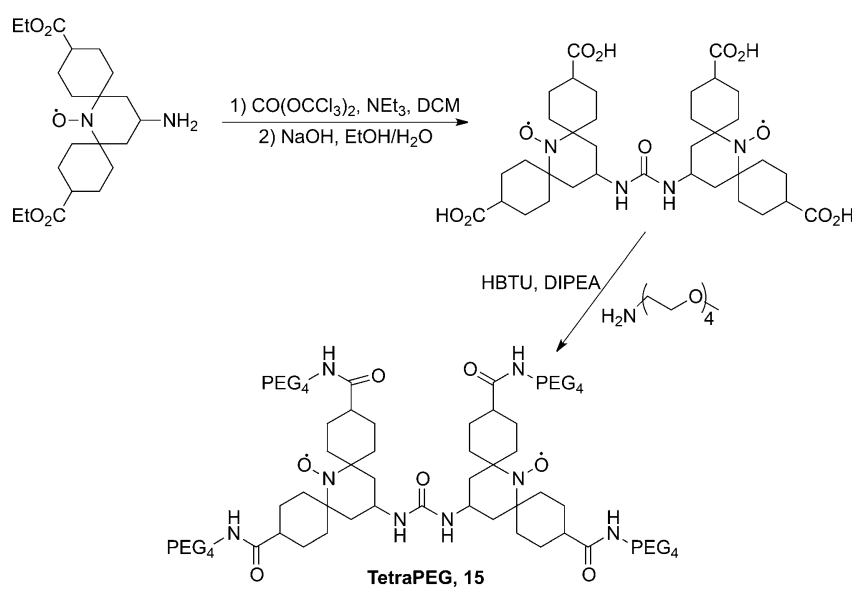

Scheme 5. Synthetic route to TetraPEG 15 (for details and compound characterization, see Section 4.5 in the Supporting Information).

Compared to those of $\mathbf{9}$ and $\mathbf{1 0}$, the $T_{1 \mathrm{e}}$ of $\mathbf{1 5}$ is dramatically higher, whereas its $T_{\mathrm{m}}$ is slightly lower. Besides the increase in molecular weight, the large increase in $T_{1 \mathrm{e}}$ probably results from a significant restriction of libration due to the extensive hydrogen-bonding network formed between the four PEG chains and the solvent. However, in spite of its much higher $T_{1 \mathrm{e}}$ (Table 2), the DNP performance of $\mathbf{1 5}$ is diminished by around $40 \%$ compared to those of 9 and 10, showing that its $T_{1 \mathrm{e}}$ far exceeds the optimal value for CE DNP efficiency. Such an effect is not observed in tetrachloroethane and the relaxation (at $95 \mathrm{GHz}, 100 \mathrm{~K}$ ) is about twice as fast for 15 as that for $9{ }^{[27]}$ suggesting that in non-hydrogen-bonding solvents the PEG chains may actually decrease the electron relaxation times, probably by inducing local motions or local softening of the glass.

For PyPoldiPEG4 11, as for bTureadiPEG2 5 and bTureadiPEG4 6 (Table 1), the changes in geometry resulting from the introduction of two PEG chains on the ureido linker induce a significant decrease in DNP enhancement.

bTurea derivatives bearing TEMPO moieties at the 1,3-positions of tetrahydropyrimidin- $2(1 H)$-one

To further rigidify the structure of bTurea-derived DNP polarizing agents, we prepared tetrahydropyrimidin-2(1H)-ones bearing TEMPO moieties at their 1,3-positions (16-18; Scheme 6).

Synthesis: Twofold reductive amination with ketone $\mathrm{E}$ and propane-1,3-diamine $\mathbf{R}$ (Scheme $6, \mathrm{R}=\mathrm{H}$ or $\mathrm{R}=\mathrm{OTBDMS}$ ) yielded compound $\mathbf{S}$, which was then cyclized with triphosgene to afford PyPolC6 $(16, \mathrm{R}=\mathrm{H})$ or $\mathrm{T}(\mathrm{R}=\mathrm{OTBDMS})$ as precursors of PyPolC6OH (17) and its PEG4 ether (18).

EPR studies: Compounds 17, 18, and AMUPol 9 showed almost identical X-band EPR spectra in water $(1 \mathrm{mM})$ at $293 \mathrm{~K}$ (Table S2 in the Supporting Information), characterized by the following calculated average parameters (Table $\mathrm{S} 3$ ): $A_{\mathrm{N}} \approx 16.4 \mathrm{G}$, $J \approx 15.5 \mathrm{G}$, with a $\delta J<4 \mathrm{G}$. The almost constant value of $J$ indicates that for these dinitroxides the average $\mathrm{e}^{-}-\mathrm{e}^{-}$distance $\left\langle R_{\mathrm{ee}}\right\rangle$ and the dipolar coupling $d$ values are also nearly the same.

CE DNP studies: The DNP results obtained with compounds 17 and 18 are reported in Table 3. The molecular weights of PyPolC6OPEG4 18 and AMUPol 9 are similar, and the longer $T_{1 \mathrm{e}}$ of the former probably results from its higher molecular rigidity. The increase in $T_{1 \mathrm{e}}$ for $\mathbf{1 8}$ is accompanied by a moderate increase in $\varepsilon$ (by a factor of ca. 1.14). The increase in $\varepsilon$ is larger for PyPolC6OH 17; however, the very long build-up time observed makes it of limited interest for DNP applications.

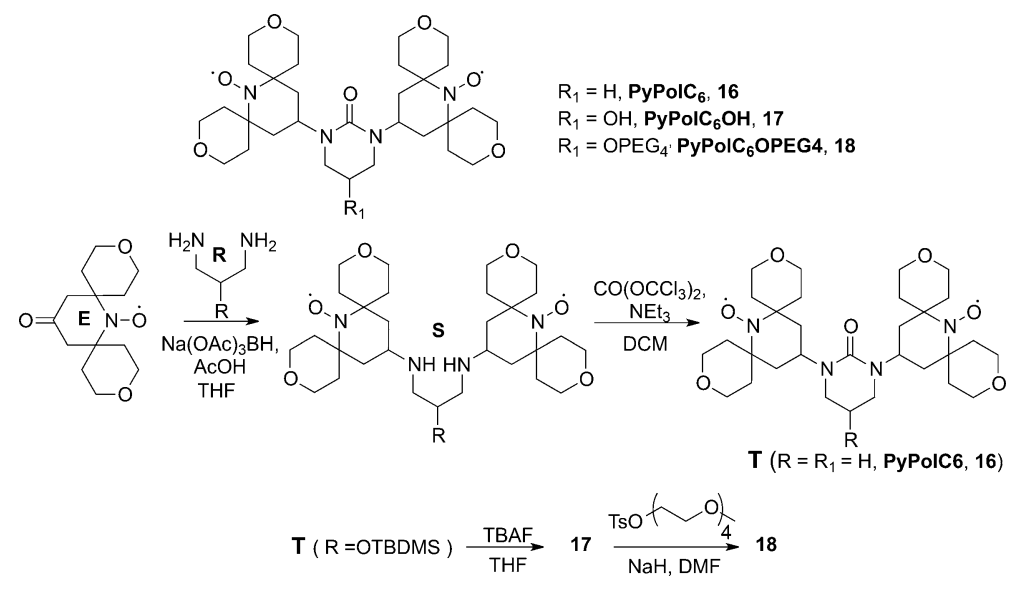

Scheme 6. Synthetic route to prepare 16, 17, and 18 (for details and compound characterization, see Section 4.6 in the Supporting Information). 


\begin{tabular}{|c|c|c|c|c|c|c|c|}
\hline Compounds & $\begin{array}{l}263 \mathrm{GHz} \\
\varepsilon\left(^{1} \mathrm{H}\right)^{[\mathrm{a}]} \\
{[-]}\end{array}$ & $\begin{array}{l}T_{\mathrm{DNP}}^{[b]} \\
{[\mathrm{s}]}\end{array}$ & $\begin{array}{l}395 \mathrm{GHz} \\
\varepsilon\left({ }^{1} \mathrm{H}\right)^{[\mathrm{aj}]} \\
{[-]}\end{array}$ & $\begin{array}{l}T_{\mathrm{DNP}}^{[b]} \\
{[\mathrm{s}]}\end{array}$ & $\begin{array}{l}T_{1 \mathrm{e}}{ }^{[\mathrm{c}]} \\
{[\mu \mathrm{s}]}\end{array}$ & $\begin{array}{l}T_{\mathrm{m}}^{[\mathrm{cc}]} \\
{[\mu \mathrm{s}]}\end{array}$ & $\begin{array}{l}\mathrm{MW} \\
{\left[\mathrm{g} \mathrm{mol}^{-1}\right]}\end{array}$ \\
\hline 9, PyPolPEG4 (AMUPol) & 244 & 3.3 & 128 & 4.9 & 445 & 2.7 & 726.9 \\
\hline 16, PyPolC6 ${ }^{[d]}$ & 62 & 1.8 & - & - & - & - & 576.7 \\
\hline 17, PyPolC6OH & 290 & 8.3 & 160 & 9.6 & - & - & 592.7 \\
\hline 18, PyPolC6OPEG4 & 278 & 3.0 & 138 & 4.3 & 612 & 2.8 & 782.9 \\
\hline
\end{tabular}

[a] $\varepsilon\left({ }^{1} \mathrm{H}\right)$ and polarization build-up time $T_{\mathrm{DNP}}$ determined from $\mathrm{CP}$ on solvent ${ }^{13} \mathrm{C}$ natural abundance. [b] Polarization build-up time $T_{\mathrm{DNP}}$ [c] In glycerol/ $/ \mathrm{D}_{2} \mathrm{O} / \mathrm{H}_{2} \mathrm{O}(60: 30: 10)$, at $95 \mathrm{GHz}, 100 \mathrm{~K},[\mathrm{C}]=10 \mathrm{~mm}$. [d] Not soluble in $\left[\mathrm{D}_{8}\right]$ glycerol/ $\mathrm{D}_{2} \mathrm{O} / \mathrm{H}_{2} \mathrm{O}(60: 30: 10)$, the reported value is for a $16 \mathrm{~mm}$ solution in tetrachloroethane (under the same conditions, $\varepsilon\left({ }^{1} \mathrm{H}\right)$ for PyPol 7 and PyPoldiMe 13 are 26 and 88, respectively).

\section{Conclusion}

We have examined a series of 18 water-soluble biradicals that are structural variants of bTurea to establish the relationship between their molecular structure and their CE DNP performance in glassy water/glycerol. The increased solubility in water of bTureaPEGns (2, 3, and 4) allows their use at higher concentrations and results in a doubling of the DNP enhancement as compared to bTurea 1.

MD calculations proved to be an interesting approach contributing to the detailed analysis of DNP performances in our bTurea series. In accordance with the high barrier of rotation about the $\mathrm{N}-\mathrm{C}(\mathrm{O})-\mathrm{N}$ bonds, for all of the calculated $\mathrm{N}_{1} \mathrm{~N}^{\prime}-\mathrm{di}$ - or tri-substituted ureas (Table $\mathrm{S} 1$ in the Supporting Information) the average e-e distance $\left(\left\langle R_{\mathrm{ee}}\right\rangle\right)$ is in the range $11.4-11.8 \AA$, which corresponds to dipolar couplings of about $32-35 \mathrm{MHz}$. The average angle $\langle\theta\rangle$ characterizing the relative orientation of the $g$ tensors is around $30^{\circ}$; however, the barrier to rotation about the $\mathrm{T}-\mathrm{NC}(\mathrm{O}) \mathrm{N}-\mathrm{T}$ bonds ( $\mathrm{T}=\mathrm{TEMPO}$ ) is weak and the fluctuation in $\theta$, amounting to about $\pm 15^{\circ}$, is significant. In this series of bTureas with almost identical $\left\langle R_{\mathrm{ee}}\right\rangle$ and $\langle\theta\rangle$ values, electron relaxation primarily governs the DNP performance, longer relaxation times leading to higher saturation factors and to better DNP performance. However, for repeated polarization transfer from the same electron spin, polarization must recover so that shorter $T_{1 \mathrm{e}}$ will increase turnover. Thus, DNP performance will reach a plateau if $T_{1 \mathrm{e}}$ becomes too long, and this is probably largely responsible for the poor DNP performance of TetraPEG 15 compared to compounds $\mathbf{9}, \mathbf{1 0}$, or 12 with significantly shorter $T_{1 \mathrm{e}}$. In the homogeneous PyPol series comprising compounds 7, 8, 9, 10, and 12, PyPolPEG2OH 12 with the longest relaxation times outperforms AMUPol (by a factor of ca. 1.2), and provides the best DNP enhancement hitherto obtained at $263 \mathrm{GHz}$ in "DNP juice". It is worthy of note that in the presence of dinitroxides, depolarization arising from sample spinning leads to a decrease in the signal intensity in MAS-DNP experiments, ${ }^{[28,29]}$ and the net sensitivity enhancement would be a more accurate parameter to compare the relative DNP performances of different dinitroxides. ${ }^{[29]}$

Adding a second PEG chain to bTureaPEG2 2 results in a drastic change in the molecular geometry, and the favored conformer(s) of bTureadiPEG2 $\mathbf{5}$ shows(show) much higher $D_{0}$ values $\left(D_{0}=-(d+J)\right)$. Even though the inequality $\left|D_{0}\right| \leqslant \omega_{0 H}$ still holds, $D_{0}$ moves away from its optimum value and, as expected ${ }^{[25,30]}$ this results in a significant decrease in the DNP enhancement. The same behavior was observed for bTureadiPEG4 6 and PyPoldiPEG4 11. The findings presented here and those reported previously suggest that a nitroxide biradical must have an $\mathrm{e}^{-}-\mathrm{e}^{-}$distance between 10 and $12 \AA$ and an angle $\langle\theta\rangle$ close to $90^{\circ}$ for maximum efficiency in CE DNP at 9.4 T.

Interestingly, the introduction of two methyl groups on the ureido linker of PyPol 7 to generate PyPoldiMe 13 does not change the $D_{0}$ value. However, a significant increase in the angle $\langle\theta\rangle$ is observed, which is accompanied by an increase in $\varepsilon$ by a factor 1.2 , even though for solubility reasons, the concentration of 13 in the DNP experiments was only half that of 7.

Lastly, it is worth noting that for bTurea derivatives having good solubility in water and giving the best DNP enhancements (such as PyPol, AMUPol, PyPolPEG10, and PyPolPE$\mathrm{G} 2 \mathrm{OH}$ ), the value of $\langle\theta\rangle$ (ca. $30 \pm 15^{\circ}$ ) is far from the value (ca. $90^{\circ}$ ) required for an optimal fit of the $\mathrm{CE}$ matching condition. Work is underway to prepare AMUPol analogues having $\langle\theta\rangle$ values around $90^{\circ}$.

\section{Experimental Section}

DNP measurements at 9.4 and $14.1 \mathrm{~T}$ were performed on Bruker solid-state DNP NMR AVANCE III HD spectrometers operating at ${ }^{1} \mathrm{H}$ frequencies of 400 and $600 \mathrm{MHz}$ and electron frequencies of 263 and $395 \mathrm{GHz}$, respectively. Samples $(25 \mu \mathrm{L})$ were packed in $3.2 \mathrm{~mm}$ sapphire rotors and measured at an MAS frequency of $8 \mathrm{kHz}$, sample temperature 100-105 K. Polarization build-up times were measured through saturation recovery experiments with continuous microwave irradiation. DNP signal enhancement was measured by comparing signal intensity with and without microwave irradiation

\section{Acknowledgements}

The research reported in this publication was supported by Université d'Aix-Marseille (AMU), the CNRS, and Bruker BioSpin. The EU COST action TD1103 on Hyperpolarization Physics and Methodology in NMR and MRI is gratefully acknowledged for stimulating interactions and travel funds. Dr. G. Gerbaud and TGE RENARD (IR-RPE CNRS 3443) are acknowledged for preliminary relaxation measurements at $35 \mathrm{GHz}$. Prof. M. Baldus is gratefully acknowledged for $527 \mathrm{GHz}$ DNP measurements at the University of Utrecht. P. Tordo and O. Ouari thank Prof. L. Emsley (EPFL Lausanne), Prof. C. Copéret (ETH Zurich), Prof. G. Jeschke (ETH Zurich) and their co-workers for valuable discussions.

Keywords: dinitroxides • molecular dynamics • organic synthesis $\cdot$ polarizing agents $\cdot$ solvent effects 
[1] a) Q. Z. Ni, E. Daviso, T. V. Can, E. Markhasin, S. K. Jawla, T. M. Swager, R. J. Temkin, J. Herzfeld, R. G. Griffin, Acc. Chem. Res. 2013, 46, $1933-$ 1941; b) A. J. Rossini, A. Zagdoun, M. Lelli, A. Lesage, C. Copéret, L. Emsley, Acc. Chem. Res. 2013, 46, 1942-1951.

[2] a) K.-N. Hu, G. T. Debelouchina, A. A. Smith, R. G. Griffin, J. Chem. Phys. 2011, 134, 125105; b) A. A. Smith, B. Corzilius, A. B. Barnes, T. Maly, R. G. Griffin, J. Chem. Phys. 2012, 136, 015101; c) K. R. Thurber, R. Tycko, J. Chem. Phys. 2012, 137, 084508; d) Y. Hovav, A. Feintuch, S. Vega, J. Magn. Reson. 2012, 214, 29-41; e) F. Mentink-Vigier, Ü. Akbey, Y. Hovav, S. Vega, H. Oschkinat, A. Feintuch, J. Magn. Reson. 2012, 224, 13-21 f) D. Shimon, Y. Hovav, A. Feintuch, D. Goldfarb, S. Vega, Phys. Chem Chem. Phys. 2012, 14, 5729-5743; g) D. Banerjee, D. Shimon, A. Fein tuch, S. Vega, D. Goldfarb, J. Magn. Reson. 2013, 230, 212-219; h) T. V. Can, M. A. Caporini, F. Mentink-Vigier, B. Corzilius, J. J. Walish, M. Rosay, W. E. Maas, M. Baldus, S. Vega, T. M. Swager, R. G. Griffin, J. Chem. Phys. 2014, 141, 064202; i) T. A. Siaw, M. Fehr, A. Lund, A. Latimer, S. A. Walker D. T. Edwards, S.-I. Han, Phys. Chem. Chem. Phys. 2014, 16, 18694 18706 ; j) D. Shimon, A. Feintuch, D. Goldfarb, S. Vega, Phys. Chem Chem. Phys. 2014, 16, 6687-6699; k) F. Mentink-Vigier, Ü. Akbey, H. Oschkinat, S. Vega, A. Feintuch, J. Magn. Reson. 2015, 258, 102-120; I) D. Mance, P. Gast, M. Huber, M. Baldus, J. Chem. Phys. 2015, 142, 234201 m) Y. Hovav, D. Shimon, I. Kaminker, A. Feintuch, D. Goldfarb, S. Vega, Phys. Chem. Chem. Phys. 2015, 17, 6053-6065.

[3] a) D. A. Hall, D. C. Maus, G. J. Gerfen, S. J. Inati, L. R. Becerra, F. W. Dahlquist, R. G. Griffin, Science 1997, 276, 930-932; b) M. Rosay, A.-C. Zeri, N. S. Astrof, S. J. Opella, J. Herzfeld, R. G. Griffin, J. Am. Chem. Soc. 2001 123, 1010-1011; c) V. S. Bajaj, M. L. Mak-Jurkauskas, M. Belenky, J. Herz feld, R. G. Griffin, Proc. Natl. Acad. Sci. USA 2009, 106, 9244-9249; d) E. Salnikov, M. Rosay, S. Pawsey, O. Ouari, P. Tordo, B. Bechinger, J. Am Chem. Soc. 2010, 132, 5940-5941; e) Ü. Akbey, W. T. Franks, A. Linden, S. Lange, R. G. Griffin, B.-J. van Rossum, H. Oschkinat, Angew. Chem. Int Ed. 2010, 49, 7803-7806; Angew. Chem. 2010, 122, 7971-7974 f) P. C. A. van der Wel, K.-N. Hu, J. Lewandowski, R. G. Griffin, J. Am. Chem. Soc. 2006, 128, 10840-10846; g) G. T. Debelouchina, M. J. Bayro, P. C. A. van der Wel, M. A. Caporini, A. B. Barnes, M. Rosay, W. E. Maas, R. G. Griffin, Phys. Chem. Chem. Phys. 2010, 12, 5911-5919; h) M. J. Bayro, G. T. Debelouchina, M. T. Eddy, N. R. Birkett, C. E. MacPhee, M Rosay, W. E. Maas, C. M. Dobson, R. G. Griffin, J. Am. Chem. Soc. 2011 133, 13967-13974; i) M. Renault, S. Pawsey, M. P. Bos, E. J. Koers, D. Nand, R. Tommassen-van Boxtel, M. Rosay, J. Tommassen, W. E. Maas, M Baldus, Angew. Chem. Int. Ed. 2012, 51, 2998-3001; Angew. Chem. 2012, 124, 3053-3056; j) H. Takahashi, I. Ayala, M. Bardet, G. De Paëpe, J.-P. Simorre, S. Hediger, J. Am. Chem. Soc. 2013, 135, 5105-5110; k) L. Reggie J. J. Lopez, I. Collinson, C. Glaubitz, M. Lorch, J. Am. Chem. Soc. 2011 133, 19084-19086; I) E. Ravera, B. Corzilius, V. K. Michaelis, C. Rosa, R. G. Griffin, C. Luchinat, I. Bertini, J. Am. Chem. Soc. 2013, 135, 1641-1644; m) J. Mao, N. Do, F. Scholz, L. Reggie, M. Mehler, A. Lakatos, Y.-S. Ong, S. J. Ullrich, L. J. Brown, R. C. D. Brown, J. Becker-Baldus, J. Wachtveitl, C. Glaubitz, J. Am. Chem. Soc. 2014, 136, 17578-17590; n) E. J. Koers, E. A. W. van der Cruijsen, M. Rosay, M. Weingarth, A. Prokofyev, C. Sauvée, O. Ouari, J. van der Zwan, O. Pongs, P. Tordo, W. E. Maas, M. Baldus, J. Biomol. NMR 2014, 60, 157-168; o) E. Ravera, B. Corzilius, V. K Michaelis, C. Luchinat, R. G. Griffin, I. Bertini, J. Phys. Chem. A 2014, 118, 2957-2965; p) K. G. Valentine, G. Mathies, S. Bedard, N. V. Nucci, I. Dodevski, M. A. Stetz, T. V. Can, R. G. Griffin, A. J. Wand, J. Am. Chem. Soc 2014, 136, 2800-2807; q) A. N. Smith, M. Caporini, G. E. Fanucci, J. R. Long, Angew. Chem. Int. Ed. 2015, 54, 1542-1546; Angew. Chem. 2015 127, 1562-1566; r) A. Potapov, W.-M. Yau, R. Ghirlando, K. R. Thurber, R. Tycko, J. Am. Chem. Soc. 2015, 137, 8294-8307; s) E. A. W. van der Cruijsen, E. J. Koers, C. Sauvée, R. E. Hulse, M. Weingarth, O. Ouari, E. Perozo, P. Tordo, M. Baldus, Chem. Eur. J. 2015, 21, $12971-12977$; t) J. Maciejko, M. Mehler, J. Kaur, T. Lieblein, N. Morgner, O. Ouari, P. Tordo, J. BeckerBaldus, C. Glaubitz, J. Am. Chem. Soc. 2015, 137, 9032-9043; u) J. Becker-Baldus, C. Bamann, K. Saxena, H. Gustmann, L. J. Brown, R. C. D. Brown, C. Reiter, E. Bamberg, J. Wachtveitl, H. Schwalbe, C. Glaubitz, Proc. Natl. Acad. Sci. USA 2015, 112, 9896-9901; v) M. Kaplan, A. Cukkemane, G. C. P. van Zundert, S. Narasimhan, M. Daniëls, D. Mance, G. Waksman, A. M. J. J. Bonvin, R. Fronzes, G. E. Folkers, M. Baldus, Nat. Methods 2015, 12, 649-652; w) K. K. Frederick, V. K. Michaelis, B. Corzilius, T.-C. Ong, A. C. Jacavone, R. G. Griffin, S. Lindquist, Cell 2015, 163,
620-628; x) Y. Su, A. Loren, R. G. Griffin, Ann. Rev. Biochem. 2015, 84, $465-497$

[4] a) M. Lelli, D. Gajan, A. Lesage, M. A. Caporini, V. Vitzthum, P. Miéville, F. Héroguel, F. Rascón, A. Roussey, C. Thieuleux, M. Boualleg, L. Veyre, G. Bodenhausen, C. Copéret, L. Emsley, J. Am. Chem. Soc. 2011, 133, $2104-$ 2107; b) O. Lafon, M. Rosay, F. Aussenac, X. Lu, J. Trébosc, O. Cristini, C. Kinowski, N. Touati, H. Vezin, J.-P. Amoureux, Angew. Chem. Int. Ed. 2011 50, 8367-8370; Angew. Chem. 2011, 123, 8517-8520; c) A. Zagdoun, A. J. Rossini, D. Gajan, A. Bourdolle, O. Ouari, M. Rosay, W. E. Maas, P. Tordo, M. Lelli, L. Emsley, A. Lesage, C. Copéret, Chem. Commun. 2012, 48,654-656; d) A. J. Rossini, A. Zagdoun, M. Lelli, J. Canivet, S. Aguado, O. Ouari, P. Tordo, M. Rosay, W. E. Maas, C. Copéret, D. Farusseng, L. Emsley, A. Lesage, Angew. Chem. Int. Ed. 2012, 51, 123-127; Angew. Chem. 2012, 124, 127-131; e) A. Zagdoun, G. Casano, O. Ouari, G. Lapadula, A. J. Rossini, M. Lelli, M. Baffert, D. Gajan, L. Veyre, W. E. Maas, M. Rosay, R. T. Weber, C. Thieuleux, C. Copéret, A. Lesage, P. Tordo, L. Emsley, J. Am. Chem. Soc. 2012, 134, 2284-2291; f) A. J. Rossini, A. Zagdoun, F. Hegner, M. Schwarzwälder, D. Gajan, C. Copéret, A. Lesage, L. Emsley, J. Am. Chem. Soc. 2012, 134, 16899-16908; g) D. Lee, H. Takahashi, A. S. L. Thankamony, J.-P. Dacquin, M. Bardet, O. Lafon, G. De Paëpe, J. Am. Chem. Soc. 2012, 134, 18491-18494; h) A. Zagdoun, A. J. Rossini, M. P. Conley, W. R. Grüning, M. Schwarzwälder, M. Lelli, W. T. Franks, H. Oschkinat, C. Copéret, L. Emsley, Angew. Chem. Int. Ed. 2013, 52, 1222 1225; Angew. Chem. 2013, 125, 1260-1263; i) A. Zagdoun, G. Casano, O. Ouari, M. Schwarzwälder, A.J. Rossini, F. Aussenac, M. Yulikov, G. Jeschke, C. Copéret, A. Lesage, P. Tordo, L. Emsley, J. Am. Chem. Soc. 2013, 135, 12790-12797; j) A. J. Rossini, C. M. Widdifield, A. Zagdoun, M. Lelli, M. Schwarzwälder, C. Copéret, A. Lesage, L. Emsley, J. Am. Chem. Soc. 2014, 136, 2324-2334; k) F. Pourpoint, A. S. L. Thankamony, C. Volkringer, T. Loiseau, J. Trébosc, F. Aussenac, D. Carnevale, G. Bodenhausen, H. Vezin, O. Lafon, J.-P. Amoureux, Chem. Commun. 2014, 50, 933-935; I) F. Ziarelli, M. Casciola, M. Pica, A. Donnadio, F. Aussenac, C. Sauvée, D. Capitani, S. Viel, Chem. Commun. 2014, 50, 10137-10139; m) F. Blanc, L. Sperrin, D. Lee, R. Dervişoğlu, Y. Yamazaki, S. M. Haile, G. De Paëpe, C. P. Grey, J. Phys. Chem. Lett. 2014, 5, 2431-2436; n) D. Le G. Casano, T. N. T. Phan, F. Ziarelli, O. Ouari, F. Aussenac, P. Thureau, G. Mollica, D. Gigmes, P. Tordo, S. Viel, Macromolecules 2014, 47, $3909-$ 3916 ; o) W. R. Gunther, V. K. Michaelis, M. A. Caporini, R. G. Griffin, Y Román-Leshkov, J. Am. Chem. Soc. 2014, 136, 6219-6222; p) L. Protesescu, A. J. Rossini, D. Kriegner, M. Valla, A. de Kergommeaux, M. Walter, K. V. Kravchyk, M. Nachtegaal, J. Stangl, B. Malaman, P. Reiss, A. Lesage, L. Emsley, C. Copéret, M. V. Kovalenko, ACS Nano 2014, 8, 2639-2648; q) P. Wolf, M. Valla, A. J. Rossini, A. Comas-Vives, F. Núñez-Zarur, B. Malaman, A. Lesage, L. Emsley, C. Copéret, I. Hermans, Angew. Chem. Int. Ed. 2014, 53, 10179-10183; Angew. Chem. 2014, 126, 10343-10347; r) G. Mollica, M. Dekhil, F. Ziarelli, P. Thureau, S. Viel, Angew. Chem. Int. Ed. 2015, 54, 6028-6031; Angew. Chem. 2015, 127, 6126-6129; s) M. Valla, A. J. Rossini, M. Caillot, C. Chizallet, P. Raybaud, M. Digne, A. Chaumonnot, A. Lesage, L. Emsley, J. A. van Bokhoven, C. Copéret, J. Am. Chem Soc. 2015, 137, 10710-10719; t) E. Ravera, V. K. Michaelis, T.-C. Ong, E. G. Keeler, T. Martelli, M. Fragai, R. G. Griffin, C. Luchinat, ChemPhysChem 2015, 16, 2751-2754; u) J. Riikonen, S. Rigolet, C. Marichal, F. Aussenac, J. Lalevée, F. Morlet-Savary, P. Fioux, C. Dietlin, M. Bonne, B. Lebeau, V-P. Lehto, J. Phys. Chem. C 2015, 119, 19272-19278; v) F. A. Perras, T. Kobayashi, M. Pruski, J. Am. Chem. Soc. 2015, 137, 8336-8339; K. Märker, M. Pingret, J.-M. Mouesca, D. Gasparutto, S. Hediger, G. De Paëpe, J. Am. Chem. Soc. 2015, 137, 13796-13799; w) L. Piveteau, T.-C. Ong, A. J. Rossini, L. Emsley, C. Copéret, M. V. Kovalenko, J. Am. Chem. Soc. 2015, 137, 13964-13971; x) Y. Geiger, H. E. Gottlieb, Ü. Akbey, H. Oschkinat, G. Goobes, J. Am. Chem. Soc. 2015, 10.1021/jacs.5b07809; y) A. C. Pinon, A. J. Rossini, C. M. Widdifield, D. Gajan, L. Emsley, Mol. Pharm. 2015, 12, 4146-4153; z) T. Kobayashi, F. A. Perras, I. I. Slowing, A. D. Sadow, M. Pruski, ACS Catal. 2015, 5, 7055-7062.

[5] a) D. S. Wollan, Phys. Rev. B 1976, 13, 3671-3685; b) D. S. Wollan, Phys. Rev. $B$ 1976, 13, 3686-3696.

[6] K.-N. Hu, H. Yu, T. M. Swager, R. G. Griffin, J. Am. Chem. Soc. 2004, 126, $10844-10845$.

[7] C. Song, K.-N. Hu, C.-G. Joo, T. M. Swager, R. G. Griffin, J. Am. Chem. Soc. 2006, 128, 11385-11390.

[8] K.-N. Hu, C. Song, H. Yu, T. M. Swager, R. G. Griffin, J. Chem. Phys. 2008, $128,052302$. 
[9] M. Rosay, L. Tometich, S. Pawsey, R. Bader, R. Schauwecker, M. Blank P. M. Borchard, S. R. Cauffman, K. L. Felch, R. T. Weber, R. J. Temkin, R. G. Griffin, W. E. Mas, Phys. Chem. Chem. Phys. 2010, 12, 5850-5860.

[10] a) Y. Matsuki, T. Maly, O. Ouari, H. Karoui, F. Le Moigne, E. Rizzato, S. Lyubenova, J. Herzfeld, T. Prisner, P. Tordo, R. G. Griffin, Angew. Chem. Int Ed. 2009, 48, 4996-5000; Angew. Chem. 2009, 121, 5096-5100; b) M Gafurov, S. Lyubenova, V. Denysenkov, O. Ouari, H. Karoui, F. L. Moigne, P. Tordo, T. Prisner, Appl. Magn. Reson. 2010, 37, 505-514.

[11] In the presence of a biradical polarizing agent, ${ }^{1} \mathrm{H}$ DNP by the CE mechanism is strongly favored when the simplified matching condition $\left(\omega_{0 \mathrm{~S}_{1}}-\omega_{0 \mathrm{~S} 2} \approx \pm \omega_{0 \mathrm{H}}\right)$ is fulfilled. ${ }^{[1 \mathrm{a}, 10,30]}$ As a consequence of $g$ tensor anisotropy $\left(g_{x x} \approx 2.0090, g_{y y} \approx 2.0060, g_{z z} \approx 2.0020\right)$, for a nitroxide biradical, the optimal matching condition will be achieved when the two $g_{\mathrm{zz}}$ (or $\left.g_{y y}\right)$ tensor axes of the nitroxide moieties have a dihedral angle of $90^{\circ}$ ( $\Delta g=0.0030$ corresponds to $\left.\Delta \omega_{S}=400 \mathrm{MHz}\right){ }^{[8,10]}$ For a nitroxide, the $z$ axis is perpendicular to the $\mathrm{CN}\left(\mathrm{O}^{\circ}\right) \mathrm{C}$ plane and the angle $\theta$ (see Table $\mathrm{S} 1$ in the Supporting Information) between the two average $\mathrm{CN}\left(\mathrm{O}^{\circ}\right) \mathrm{C}$ planes of a nitroxide biradical appears to be a reliable characterization of the relative orientation of the $g_{1}$ and $g_{2}$ tensors.

[12] E. L. Dane, B. Corzilius, E. Rizzato, P. Stocker, T. Maly, A. A. Smith, R. G. Griffin, O. Ouari, P. Tordo, T. M. Swager, J. Org. Chem. 2012, 77, 17891797.

[13] M. K. Kiesewetter, B. Corzilius, A. A. Smith, R. G. Griffin, T. M. Swager, J. Am. Chem. Soc. 2012, 134, 4537-4540.

[14] a) J. Mao, D. Akhmetzyanov, O. Ouari, V. Denysenkov, B. Corzilius, J. Plackmeyer, P. Tordo, T. F. Prisner, C. Glaubitz, J. Am. Chem. Soc. 2013, 135, 19275-19281; b) M. K. Kiesewetter, V. K. Michaelis, J. J. Walish, R. G. Griffin, T. M. Swager, J. Phys. Chem. A 2014, 118, 1825-1830; c) M. Lelli, A. J. Rossini, G. Casano, O. Ouari, P. Tordo, A. Lesage, L. Emsley, Chem. Commun. 2014, 50, 10198-10201.

[15] a) C. Ysacco, E. Rizzato, M. A. Virolleaud, H. Karoui, A. Rockenbauer, F. Le Moigne, D. Siri, O. Ouari, R. G. Griffin, P. Tordo, Phys. Chem. Chem. Phys. 2010, 12, $5841-5845$; b) C. Ysacco, H. Karoui, G. Casano, F. Le Moigne, S. Combes, A. Rockenbauer, M. Rosay, M. Werner, O. Ouari, P. Tordo, Appl. Magn. Reson. 2012, 43, 251.

[16] E. G. Rozantsev, V. A. Golubev, M. V. Neiman, Y. V. Kokhanov, Izv. Akad. Nauk Arm. SSR Khim. Nauki 1965, 572-573.

[17] C. Sauvée, M. Rosay, G. Casano, F. Aussenac, R. T. Weber, O. Ouari, P. Tordo, Angew. Chem. Int. Ed. 2013, 52, 10858-10861; Angew. Chem. 2013, 125, 11058-11061.

[18] V. K. Michaelis, T.-C. Ong, M. K. Kiesewetter, D. K. Frantz, J. J. Walish, E. Ravera, C. Luchinat, T. M. Swager, R. G. Griffin, Isr. J. Chem. 2014, 54, 207-221.
[19] D. J. Kubicki, A. J. Rossini, A. Purea, A. Zagdoun, O. Ouari, P. Tordo, F. Engelke, A. Lesage, L. Emsley, J. Am. Chem. Soc. 2014, 136, 15711-15718.

[20] E. Bouleau, P. Saint-Bonnet, F. Mentink-Vigier, H. Takahashi, J.-F. Jacquot M. Bardet, F. Aussenac, A. Purea, F. Engelke, S. Hediger, D. Lee, G. De Päepe, Chem. Sci. 2015, 6, 6806-6812.

[21] a) K. R. Thurber, W. M. Yau, R. Tycko, J. Magn. Reson. 2010, 204, $303-$ 313; b) W. M. Yau, K. R. Thurber, R. Tycko, J. Magn. Reson. 2014, 244, 98 106.

[22] a) R. Briere, R. Dupeyre, H. Lemaire, C. Morat, A. Rassat, P. Rey, Bull. Soc. Chim. Fr. 1965, 3290-3297; b) G. R. Luckhurst, Mol. Phys. 1966, 10, $543-$ 550; c) G. R. Luckhurst, G. F. Pedulli, J. Am. Chem. Soc. 1970, 92, $4738-$ 4739; d) P. H. Rieger, in Electron Spin Resonance: Analysis and Interpretation, RSC Publishing, Cambridge, 2007, pp. 112-117; e) M. F. Ottaviani, A. Modelli, O. Zeika, S. Jockusch, A. Moscatelli, N. J. Turro, J. Phys. Chem A 2012, 116, 174-184; f) D. Bardelang, G. Casano, F. Poulhès, H. Karoui, J. Filippini, A. Rockenbauer, R. Rosas, V. Monnier, D. Siri, A. Gaudel-Siri, O. Ouari, P. Tordo, J. Am. Chem. Soc. 2014, 136, 17570-17577.

[23] a) T. Strassner, Mol. Model. Annu. 1996, 2, 217-226; b) V. S. Bryantsev, T. K. Firman, B. P. Hay, J. Phys. Chem. A 2005, 109, 832-842; c) M. Obrzud, M. Rospenk, A. Koll, J. Phys. Chem. B 2010, 114, 15905-15912.

[24] B. Hess, C. Kutzner, D. van der Spoel, E. Lindahl, J. Chem. Theory Comput 2008, 4, 435-447.

[25] T. V. Can, Q. Z. Ni, R. G. Griffin, J. Magn. Reson. 2015, 253, 23-35.

[26] a) H. Sato, V. Kathirvelu, A. Fielding, J. P. Blinco, A. S. Micallef, S. E. Bottle, S. S. Eaton, G. R. Eaton, Mol. Phys. 2007, 105, 2137-2151; b) J. L. Du, G. R. Eaton, S. S. Eaton, J. Magn. Reson. Ser. A 1995, 115, 213-221; c) A Zecevic, G. R. Eaton, S. S. Eaton, M. Lindgren, Mol. Phys. 1998, 95, $1255-$ 1263 ; d) A. Rajca, V. Kathirvelu, S. K. Roy, M. Pink, S. Rajca, S. Sarkar, S. S. Eaton, G. R. Eaton, Chem. Eur. J. 2010, 16, 5778-5782.

[27] D. J. Kubicki, G. Casano, M. Schwarzwälder, S. Abel, C. Sauvée, K. Ganesan, M. Yulikov, A. J. Rossini, G. Jeschke, C. Copéret, A. Lesage, P. Tordo, O. Ouari, L. Emsley, Chem. Sci. 2016, 7, 550-558.

[28] K. R. Thurber, R. Tycko, J. Chem. Phys. 2014, 140, 184201-184211.

[29] F. Mentink-Vigier, P. Subhradip, D. Lee, A. Feintuch, S. Hediger, S. Vega, G. De Paëpe, Phys. Chem. Chem. Phys. 2015, 17, 21824-21836.

[30] G. Mathies, M. A. Caporini, V. K. Michaelis, Y. Liu, K.-N. Hu, D. Mance, J. L. Zweier, M. Rosay, M. Baldus, R. G. Griffin, Angew. Chem. Int. Ed. 2015, 54, 11770; Angew. Chem. 2015, 127, 11936.

Received: November 21, 2015

Published online on II, 0000 


\section{FULL PAPER}

\section{Polarizing Agents}

C. Sauvée, G. Casano, S. Abel,

A. Rockenbauer, D. Akhmetzyanov,

H. Karoui, D. Siri, F. Aussenac, W. Maas,

R. T. Weber, T. Prisner, M. Rosay, P. Tordo, *

O. Ouari*

口-

Tailoring of Polarizing Agents in the bTurea Series for Cross-Effect Dynamic Nuclear Polarization in Aqueous Media

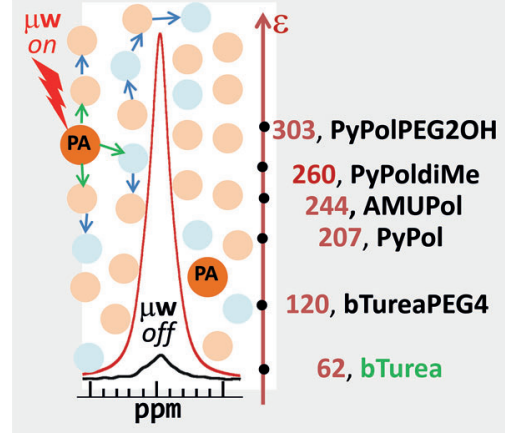

Improved polarizing agents: A series of 18 dinitroxide biradicals derived from bTurea has been prepared, and their performances as polarizing agents in cross-effect dynamic nuclear polarization (CE DNP) NMR experiments at 9.4 and $14.1 \mathrm{~T}$ and $100 \mathrm{~K}$ in a DNP-optimized glycerol/water matrix have been studied. The DNP performance is strongly correlated with the substituents on the polarizing agents (see graphic), and its trend is discussed in terms of different molecular parameters. 